\title{
Helping to Clarify Mechanical Ventilation Protocols
}

Protocols in the ICU have become quite commonplace, thanks to studies like the one we have in this issue of RESPIRATORY CARE. It has been recommended by a collective task force that we utilize a mechanical ventilation weaning protocol. ${ }^{1}$ Many papers have focused on this topic since it was proved, in 1984, that such protocols can work in extubating patients faster after cardiac surgery. ${ }^{2}$

\section{See the Original Study on Page 170}

When to discontinue mechanical ventilation is a large part of the work we do in the ICU every day. For patients, a large part of the time spent on mechanical ventilation is in the weaning process. Typically, the decision to start weaning is primarily physician-dependent, and, much to the chagrin of many physicians, studies have revealed that a well designed protocol is better for our patients and hospital systems. Early discontinuation of mechanical ventilation decreases morbidity and costs. Many reviews have been done, including Girard and Ely's, in 2008, which revealed many benefits, including decreases in ventilator and weaning time, ICU costs, complications, ICU and hospital stay, ventilator-associated pneumonia, and improved survival. ${ }^{3}$ In a busy ICU, protocols can help free up time to work on more critical patients. Patients who are in the weaning process typically suffer in a busy ICU because they are deemed stable. A protocol keeps this process going and requires minimal physician input until the patient is ready for discontinuation from the ventilator. A protocol also standardizes care by reducing practice variability; I am sure we have all worked in an ICU where each physician has his or her own way of managing care.

Most protocols begin by assessing whether the patient's etiology of respiratory failure has improved and the patient is stable for weaning. If so, the patient undergoes a spontaneous breathing trial. A spontaneous breathing trial was identified as the superior method of weaning by Esteban and colleagues, in $1995 .{ }^{4}$ The spontaneous breathing trial is typically coupled with a daily wake-up from sedation, and this combination has been shown to improve outcomes in the ICU. ${ }^{5}$ This is usually followed by a pressure support or CPAP trial with minimal pressure support or PEEP. The patient is then extubated if he or she meets the criteria set forth by the protocol, and only with a physician order.
In this issue of Respiratory CARe, Gupta et al reinforce the fact that protocols are our best option in weaning mechanical ventilation in most patients. ${ }^{6}$ This was a large study, evaluating the outcomes of a respiratory-therapistdriven protocol versus physician-driven orders in patients with simple and difficult mechanical ventilation weaning. The study revealed an improvement in ventilator-free days, by $20 \%$ in the simple-weaning patients, and $68 \%$ in the difficult-weaning patients, and both those differences were statistically significant. The smaller improvement in the patients with simple weaning was likely expected, as most of these patients do not spend much time on the ventilator. Though the decrease in time spent on mechanical ventilation was statistically significant in the difficult-weaning group, patients in this category are felt to represent only about $16 \%$ of patients on mechanical ventilation. ${ }^{7}$ This was the exact number seen in the Gupta et al study as well. The control group subjects received usual care, provided by physicians who opted out of the study. This is the exact reason protocols have been implemented in many hospitals, as usual care is not always the standard of care, and not much is said of the care the control group received. This is the first study to address a weaning protocol in patients broken up into simple versus difficult weaning groups. It was first recommended to stratify these patients into 3 groups by a task force of the Sixth International Consensus Conference on Intensive Care Medicine. ${ }^{7}$ This may help to decide which patients may benefit from weaning protocols.

As with many topics in the healthcare system, there are controversies concerning weaning protocols and all protocols. The studies that have shown no benefit are mostly in specific patient groups, such as neurosurgical, trauma, or pediatric ICU patients, though there have also been studies in these groups that have been successful. The study in this issue of RESPIRATORY CARE included a mixed patient population and corresponds to most of the literature on weaning protocols. One study in a mixed ICU that did not find a significant difference with a weaning protocol benefitted from very high physician staffing to patient ratio. The level of staffing was 9.5 physician-hours per bed per day. ${ }^{8}$ If only we all worked in hospitals that could afford that amount of staffing.

Protocols have been criticized that they replace clinical judgment and are "cookie cutter" medicine. In the study by Gupta et $\mathrm{al}^{6}{ }^{6}$ and in most other such studies, the order to extubate is still done by a physician, and this is something that needs to be done at the bedside. This is where clinical 


\section{Helping to Clarify Mechanical Ventilation Protocols}

judgment comes into play. A weaning protocol is mostly designed to get the weaning process started as soon as is safely possible, instead of waiting for when the physician feels it can be started. We also must remember that once a protocol is in place we still need to police ourselves when we are using it. Many studies have shown poor adherence to protocols, which will negate the benefits. Education of staff is also a key point in the implementation. If we want to continue to stay the course with evidence-based medicine, we must continue to find ways to implement and standardize our practice. Protocols serve this purpose well and still require the input from the entire ICU team, without compromising care or clinical judgment.

Alan J Kanouff DO

Lung Disease Center of Central Pennsylvania

Altoona, Pennsylvania

Dr Kanouff has disclosed a relationship with Forest Pharmaceuticals.

Correspondence: Alan J. Kanouff DO, Lung Disease Center of Central Pennsylvania,800Chestnut Avenue, Altoona PA 16601.E-mail: Ajk145@ hotmail.com.

DOI: $10.4187 /$ respcare.03061

\section{REFERENCES}

1. MacIntyre NR, Cook DJ, Ely EW Jr, Epstein SK, Fink JB, Heffner $\mathrm{JE}$, et al. Evidence-based guidelines for weaning and discontinuing ventilator support: a collective task force facilitated by the American College of Chest Physicians; the American Association for Respiratory Care, and the American College of Critical Care Medicine. Chest 2001;120(6 Suppl):375S-395S.

2. Foster GH, Conway WA, Pamulkov N, Lester JL, Magilligan DJ Jr. Early extubation after coronary artery bypass: brief report. Crit Care Med 2006;12(11):994-996.

3. Girard TD, Ely EW. Protocol-driven ventilator weaning: reviewing the evidence. Clin Chest Med 2008;29(2):241-252.

4. Esteban A, Frutos F, Tobin MJ, Alía I, Solsona JF, Valverdú V, et al. A comparison of four methods of weaning patients from mechanical ventilation. N Engl J Med 1995;332(6):345-350.

5. Girard TD, Kress JP, Fuchs BD, Thomason JW, Schweikert WD, Pun BT, et al. Efficacy and safety of a paired sedation and ventilator weaning protocol for mechanically ventilated patients in intensive care (Awakening and Breathing Controlled trial): a randomized controlled trial. Lancet 2008;371(9607):126-134.

6. Gupta P, Giehler K, Walters RW, Meyerink K, Modrykamien AM. The effect of a mechanical ventilation discontinuation protocol in patients with simple and difficult weaning: impact on clinical outcomes. Respir Care 2013;59(2):170-177.

7. Boles JM, Bion J, Connors A, Herridge M, Marsh B, Melot C, et al. Weaning from mechanical ventilation. Eur Respir J 2007;295(5): 1033-1056.

8. Krishnan JA, Moore D, Robeson C, Rand CS, Fessler HE. A prospective, controlled trial of a protocol-based strategy to discontinue mechanical ventilation. Am J Respir Crit Care Med 2004;169(6): 673-678. 